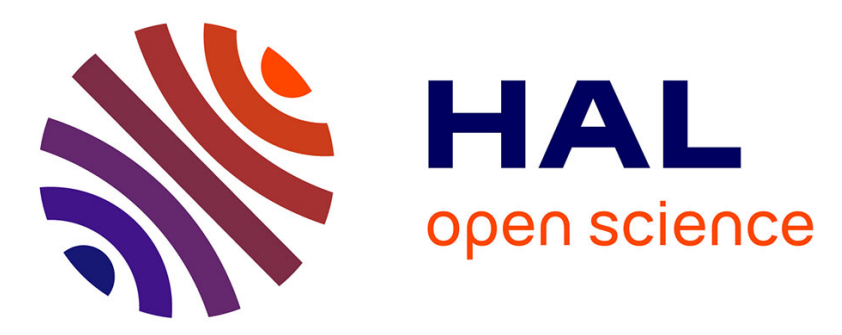

\title{
The influence of ionothermal synthesis using BmimBF4 as a solvent on nanophosphor BaFBr:Eu2+ photoluminescence
}

\author{
Jacob Olchowka, Teresa Delgado, Hans Hagemann, Claudia Wickleder
}

\section{To cite this version:}

Jacob Olchowka, Teresa Delgado, Hans Hagemann, Claudia Wickleder. The influence of ionothermal synthesis using BmimBF4 as a solvent on nanophosphor BaFBr:Eu2+ photoluminescence. Nanoscale, 2018, 10 (42), pp.19706-19710. 10.1039/C8NR06842A . hal-02143445

\section{HAL Id: hal-02143445 \\ https://hal.science/hal-02143445}

Submitted on 28 Jan 2021

HAL is a multi-disciplinary open access archive for the deposit and dissemination of scientific research documents, whether they are published or not. The documents may come from teaching and research institutions in France or abroad, or from public or private research centers.
L'archive ouverte pluridisciplinaire $\mathbf{H A L}$, est destinée au dépôt et à la diffusion de documents scientifiques de niveau recherche, publiés ou non, émanant des établissements d'enseignement et de recherche français ou étrangers, des laboratoires publics ou privés. 


\title{
Influence of ionothermal synthesis using $\mathrm{BmimBF}_{4}$ as solvent on nanophosphors BaFBr:Eu ${ }^{2+}$ photoluminescence
}

\author{
Jacob Olchowka*, Hans Hagemann, Teresa Delgado, Claudia Wickleder *
}

Dr. J. Olchowka, Prof. H. Hagemann, Dr. T. Delgado

Département de Chimie-Physique, Université de Genève, CH-1211 Geneva 4, Switzerland

Prof. Claudia Wickleder

University of Siegen Department Chemistry/Biology, Faculty of Science and Technology, 57068 Siegen, Germany.

Corresponding Author e-mail: jacob.olchowka@icmcb.cnrs.fr

Keywords: Ionothermal synthesis, nano-phosphors, time resolved spectroscopy, fluorides

Abstract: Ionothermal synthesis is a strongly growing research area due to the outstanding physical and chemical properties of ionic liquid (IL) to design new materials, however, the interaction of these ILs molecules with optical materials and their effect on the luminescence properties of the materials is poorly known. In this work, it is shown that the imidazolium based $\mathrm{BmimBF}_{4}$ ionic liquid, used as a solvent during the synthesis, tethers at the surface of the nanoparticles and influences the photoluminescence of the nanophosphor $\mathrm{BaFBr}: \mathrm{Eu}^{2+}$ materials. By time resolved spectroscopy two different emissions are observed for the material synthesized by ionothermal approach, one corresponding to $\mathrm{Eu}(\mathrm{II}) 5 \mathrm{~d}-4 \mathrm{f}$ transitions in $\mathrm{BaFBr}$ host with a decay time of $843 \mathrm{~ns}$ and the other with a much faster decay time to the ionic liquid $\mathrm{BmimBF}_{4}$.

The-research of new nano-phosphors and more generally of nanostructured inorganic material,-which require novel synthetic approaches, are currently a very hot topic in the context of energy saving and expanding nanotechnology. ${ }^{[1-5]}$ Among the new original synthesis approaches, ionothermal synthesis becomes unavoidable due to the unique and remarkable properties of the ionic liquids (IL). ${ }^{[6,7]}$ For instance ILs have high dissolving 
ability, low vapor pressure, good thermal stability and they are good microwave absorbers due to their polar character which makes them gripping solvent media. ${ }^{[8]}$ Furthermore, they can also be used as template to control the size and morphology of the materials, as stabilizing agent to avoid particles agglomeration and also as reactant in order to be (partially) incorporated in the synthesized final material. ${ }^{[9-15]}$

Additionally, the physical and chemical properties of ionic liquids can be tailored according to the requirements by playing on its chemical composition (nature of cationic and/or anionic part, number, position and/or length of alkyl chain, and some more) in order to design the desired solvent. ${ }^{[16-18]}$ Finally, their unique properties can provide reaction conditions that cannot be obtained with traditional solvents and hence, new inorganic and also organicinorganic hybrid materials can be designed.

During the last years, oxides, (oxy)hydroxides, fluorides, chalcogenides or even metal nanoparticles targeting different application areas (e.g. energy storage, photoluminescence, photocatalysis) have been successfully developed by ionothermal synthesis. ${ }^{[19-25]}$ Most of the time these materials exhibit very interesting properties; for instance, $\mathrm{Co}(\mathrm{OH})_{2}$-IL obtained by preparation in $\mathrm{BmimBF}_{4}$ nearly doubles the specific capacitance and remarkably improves the cycling stability compared to $\mathrm{Co}(\mathrm{OH})_{2} \cdot{ }^{[21]}$ Another example is $\mathrm{TiO}_{2}$ synthesized in ionic liquid media, which demonstrates enhanced photocatalytic $\mathrm{H}_{2}$ generation. ${ }^{[21,26]}$

Concerning luminescent materials, we have recently demonstrated an efficient one-pot microwave and/or sonochemical approach to obtain fluoridic Eu(II) doped nanocrystals using ionic liquid as solvent, template and fluoride source in order to avoid a harmful reactant such as $\mathrm{HF}$ or even elemental fluorine. ${ }^{[27,28]}$ We used $\mathrm{Eu}(\mathrm{II})$ compounds as starting materials, so that the "reducing" character of $\mathrm{BmimBF}_{4}$ prevents $\mathrm{Eu}(\mathrm{II})$ oxidation during the microwave and/or sonochemical synthesis. The decomposition of $\mathrm{BF}_{4}^{-}$liberates fluoride ions which are used as a reactant. ${ }^{[20]}$ During the synthesis, the acidic hydrogen from the imidazolium ring bonds with the highly electronegative halogen to form an IL shell around the barium 
fluorohalide material. ${ }^{[29]}$ This protective shell prevents nanoparticles agglomeration, its formation is assumed to be favored by the sonochemical effect and the low temperature synthesis. ${ }^{[29]}$ The presence of ionic liquids molecules on the surface can enhance electrochemical properties by allowing faster ion diffusion and easier hydrogen desorption/adsorption processes. ${ }^{[21]}$ Furthermore, it can cause great prospects in catalytic reactions. In contrast the influence of ionic liquids on photoluminescence properties of materials is poorly known. ${ }^{[30-32]}$ Moreover, some ionic liquids including $\mathrm{BmimBF}_{4}$ exhibit visible emission, hence it is well-founded that it can affect the photoluminescence of the core material. ${ }^{[33,34]}$

Through this work we will highlight the application of IL during the synthesis of nanoparticles by investigating the luminescent properties of $\mathrm{BaFBr}^{\mathrm{E}} \mathrm{Eu}^{2+}$ nanoparticles synthesized by ionothermal synthesis in detail. $\mathrm{BaFBr}_{\mathrm{Eu}}{ }^{2+}$ is a well-known phosphor, its luminescence was widely studied and this material is used as detector in imaging plate thanks due its high density $\left(\sim 5 \mathrm{~g} / \mathrm{cm}^{3}\right)$ for a long time. Its $\mathrm{K}$-edge of $37 \mathrm{keV}$ is well suited for general radiography, and a short lifetime due to the parity allowed transitions of $\mathrm{Eu}(\mathrm{II})$ is observed. ${ }^{[35-39]}$ Our results on $\mathrm{BaFBr}: \mathrm{Eu}^{2+}$ nanoparticles will lead, thus, also to commercial impacts due to improving of spatial resolution compared to the bulk $\mathrm{BaFBr}: \mathrm{Eu}^{2+}$ phosphors currently used for imaging plates. ${ }^{[38-40]}$

In this paper, transmission electron microscopy images of $\mathrm{BaFBr}_{\mathrm{Eu}}{ }^{2+}$ synthesized by ionothermal approach show that the particles are platelet-like and tend to agglomerate (see Figure 1a and Figure S2). These agglomerates (typical size of a couple of micrometers) are composed by polydispersed nanocrystalline platelets ranging from few tens of nanometers to some hundreds of nanometers length (see Figure 1b).

Fourier transformed infrared measurements of $\mathrm{BaFBr}: \mathrm{Eu}^{2+}$ and $\mathrm{EDX}$ analyses confirmed the presence of ionic liquid $\left(\mathrm{BmimBF}_{4}\right)$ attached to the surface of the material, even after several washing steps with water and ethanol (see Figure 2 and Figure S3). Compared to the spectrum 
of pure $\mathrm{BmimBF}_{4}$, the vibrations, which belong to its alkyl C-H stretching (below $3000 \mathrm{~cm}^{-1}$ ), remain unchanged and those attributed to the ring $\mathrm{C}-\mathrm{H}$ stretching $\left(3121\right.$ and $\left.3161 \mathrm{~cm}^{-1}\right)$ slightly shift to lower frequency. ${ }^{[41]}$ This can be explained by the fact, that acidic hydrogen from imidazolium bonds to electronegative halides. ${ }^{[29]}$ On the other hand, the vibrations attributed to $\mathrm{BF}_{4}$ stretching are shifted to higher frequency in the case of the nanoparticles. This can be interpreted by an increase of the B-F covalency, which is influenced by the interaction between the surface of $\mathrm{BaFBr}$ and the ionic liquid. The vibrations corresponding to $\mathrm{BaFBr}: \mathrm{Eu}^{2+}$ cannot be detected by our FTIR since they are localized between 100 and $300 \mathrm{~cm}^{-}$ ${ }^{1}$, below our instrumental wavenumber range. ${ }^{[42]}$ However, Raman spectra in the range of 100 and $300 \mathrm{~cm}^{-1}$ confirm the presence of $\mathrm{BaFBr}$, in agreement with the reported Raman spectra for $\mathrm{BaFBr}$ (Figure S4). ${ }^{[43]}$

In order to investigate the effects of the IL molecules attached to the $\mathrm{BaFBr}$ nanoparticles surface on the photoluminescence (PL) properties, luminescence, decay time and timeresolved spectroscopy measurements were performed. At a first sight, the room temperature PL spectrum is similar to the one observed for bulk $\mathrm{BaFBr}$ and nanosized materials obtained by other synthetic approaches. ${ }^{[36,37,42]}$ It exhibits an intense blue emission band peaking around $390 \mathrm{~nm}$ (see Figure 3). However, a closer inspection reveals a low intensity tail at longer wavelength (see inset in figure 3). In the literature, impurity band emissions attributed to oxygen defects can be found, however, they are usually situated at longer wavelength and can be strongly visible under $250-260 \mathrm{~nm}$ excitation. ${ }^{[42,44-46]}$ In the material synthesized by ionothermal approach, photoluminescence measurements performed under $260 \mathrm{~nm}$ excitation did not reveal any change in the emission spectrum (Figure S5) which allow to assume that there is no (detectable) oxygen defects in our samples. In order to have more information about the origin of this tail, decay time measurements were performed. The decay time curve has a mono-exponential behavior fitted to $\tau_{400 \mathrm{~nm}}=843 \mathrm{~ns}\left( \pm 1 \mathrm{~ns}\right.$ and $\left.\mathrm{R}^{2}=0.99\right)$ when exciting 
at $266 \mathrm{~nm}$ and monitoring the emission at $400 \mathrm{~nm}$. On the other hand, the life time is fitted to approximatively $\tau_{500 \mathrm{~nm}}=6 \mathrm{~ns}( \pm 0.2)$ when the detection is set at $500 \mathrm{~nm}$, where still some emission intensity can be detected (see Figure 4 and Figure S6).

These results confirm that there are at least two emissions with different origins. The lifetime of $843 \mathrm{~ns}$ is in agreement with the parity allowed $5 \mathrm{~d}-4 \mathrm{f}$ transition of Eu(II) and it is also in good accordance to the literature lifetime of $\mathrm{BaFBr}: \mathrm{Eu}^{2+}$ whereas the other decay time of $6 \mathrm{~ns}$ is quite too short to assign to divalent europium emission. ${ }^{[37,42,47]}$ For instance, Hesse et al. found decay time of $770 \mathrm{~ns}$ for bulk $\mathrm{BaFBr}_{\mathrm{Eu}}{ }^{2+}(0.1 \mathrm{~mol} \%)$ and Liang et al. descript a decay time of $600 \mathrm{~ns}$ for BaFBr: $\mathrm{Eu}^{2+}(0.92 \mathrm{~mol} \%)$ micro-platelets. ${ }^{[37,42]}$ In our case, the nanosized character of our samples conjugated to a higher doping concentration does not drop the $\mathrm{Eu}^{2+,} \mathrm{s}$ decay time as it could be expected. On the opposite, it is slightly higher than the decay time values described above. This circumstance can be explained by the fact that the ionic liquid shell prevents the formation of nanoparticle surface defects by a rather large amount, which would lead to quenching effects of the PL and decrease the decay time. Moreover, it can be assumed, that the IL shell also prevent quenching due to e.g. water or alcoholic molecules attached to the surface if they are used as solvents.

Time resolved spectroscopy measurements also confirm the origin of the two different emissions. With a detection gate of 53-1800 ns, the typical blue emission of $\mathrm{Eu}(\mathrm{II})$ in $\mathrm{BaFBr}$ is observed whereas with a gate of $0-27 \mathrm{~ns}$, where no $\mathrm{Eu}(\mathrm{II})$ emission is available, another broad emission band peaking at $425 \mathrm{~nm}$ is detected (see Figure 5). This very fast emission is comparable to the one of pure $\mathrm{BmimBF}_{4}$ in the inset Figure 5. The comparison shows that even if the emission of pure the ionic liquid (black curve) is slightly shifted $\left(\Delta \mathrm{E}=540 \mathrm{~cm}^{-1}\right)$ to longer wavelengths and has a longer tail, the two emission bands are similar both in energy position and in shape. Hence, it is reasonable to attribute the second emission to $\mathrm{BmimBF}_{4}$. The interactions between the ionic liquid and the surface of the barium fluorobromide most probably induce a shift of the emission band and explain the differences between the emission 
of the ionic liquid grafted on the $\mathrm{BaFBr}$ surface and the pure $\mathrm{BmimBF}_{4}$. Additionally, the lifetime of few nanoseconds fits well with the reported one for $\pi-\pi^{*}$ transitions from imidazolium cation in $\mathrm{BmimBF}_{4}{ }^{[33]}$

The very short lifetime conjugated to the energy position of the second emission band peaking at $420 \mathrm{~nm}$ exclude the possibility that oxygen centres ( $\mathrm{F}$ centres), which are often found in $\mathrm{BaFBr}$, are responsible for the second emission band. ${ }^{[37,44,46,48]}$ The PL emission originating from these defects (F centres) is situated at longer wavelengths and has a life time in the range of microseconds. ${ }^{[37]}$

In summary, our spectroscopic experiments demonstrate that two distinct emission bands could be detected for BaFBr:Eu ${ }^{2+}$ nanoparticles synthesized by ionothermal method. In detail, a blue emission band is observed assigned to the $5 \mathrm{~d} \rightarrow 4 \mathrm{f}$ transition of $\mathrm{Eu}(\mathrm{II})$ ions doped in the $\mathrm{BaFBr}$ host, while the other could be attributed to $\mathrm{BmimBF}_{4}$ attached on the material surface. This led to the conclusion that the ionic liquid shell formed during the synthesis also shows light emission and hence, influences the photoluminescence of the phosphor material. We believe that these results do not concern only this specific example but that they can most probably be extended to several phosphors synthesized using ionic liquids as solvents and improve their properties. The intimate contact between ionic liquid and inorganic phosphor can thus contribute in general to decrease quenching processes for nanoparticles, this is a very important point in our opinion.

\section{Acknowledgements}

This work was funded by the German Science Foundation (Priority program SPP 1708 "Material Synthesis near Room Temperature") and by SNF (Project number: 200021_169033). The authors are thankful to Professor Andreas Hauser for his help with time resolved spectroscopy measurements. 
References

[1] H. Terraschke, C. Wickleder, Chem. Rev. 2015, 115, 11352-11378.

[2] Z. Xia, Z. Xu, M. Chen, Q. Liu, Dalt. Trans. 2016, 45, 11214-11232.

[3] A. Mnoyan, Y. Lee, H. Jung, S. Kim, Phosphors, Up Conversion Nano Particles, Quantum Dots and Their Applications, 2016.

[4] K. Tauni Dissanayake, F. A. Rabuffetti, Chem. Mater. 2018, 30, 2453-2462.

[5] Z. Liu, M. A. Stevens-Kalceff, X. Wang, H. Riesen, Chem. Phys. Lett. 2013, 588, 193197.

[6] S. Handy, Curr. Org. Chem. 2005, 9, 959-988.

[7] R. E. Morris, Chem. Commun. 2009, 0, 2990.

[8] C. Janiak, AIMS Mater. Sci. 2014, 1, 41-44.

[9] M. F. Groh, A. Wolff, M. A. Grasser, M. Ruck, Int. J. Mol. Sci. 2016, 17, 1452.

[10] X. Kang, X. Sun, X. Ma, P. Zhang, Z. Zhang, Q. Meng, B. Han, Angew. Chemie - Int. Ed. 2017, 56, 12683-12686.

[11] J. Olchowka, M. Suta, C. Wickleder, Chem. - A Eur. J. 2017, 23, 12092-12095.

[12] D. Freudenmann, S. Wolf, M. Wolff, C. Feldmann, Angew. Chemie - Int. Ed. 2011, 50, $11050-11060$.

[13] X. Kang, X. Sun, B. Han, Adv. Mater. 2016, 28, 1011-1030.

[14] K. Qi, W. Zheng, Curr. Opin. Green Sustain. Chem. 2017, 5, 17-23.

[15] S. Wegner, C. Janiak, Metal Nanoparticles in Ionic Liquids, Springer International Publishing, 2017.

[16] K. Ghandi, Green Sustain. Chem. 2014, 04, 44-53.

[17] G. G. Eshetu, M. Armand, H. Ohno, B. Scrosati, S. Passerini, Energy Environ. Sci. 2016, 9, 49-61.

[18] E. Mourad, L. Coustan, P. Lannelongue, D. Zigah, A. Mehdi, A. Vioux, S. A. Freunberger, F. Favier, O. Fontaine, Nat. Mater. 2016, 16, 446-453. 
[19] N. Recham, J. N. Chotard, J. C. Jumas, L. Laffont, M. Armand, J. M. Tarascon, Chem. Mater. 2010, 22, 1142-1148.

[20] P. Barpanda, M. Ati, B. C. Melot, G. Rousse, J. N. Chotard, M. L. Doublet, M. T. Sougrati, S. A. Corr, J. C. Jumas, J. M. Tarascon, Nat. Mater. 2011, 10, 772-779.

[21] B. G. Choi, M. Yang, S. C. Jung, K. G. Lee, J. G. Kim, H. Park, T. J. Park, S. B. Lee, Y. K. Han, Y. S. Huh, ACS Nano 2013, 7, 2453-2460.

[22] N. Recham, L. Dupont, M. Courty, K. Djellab, D. Larcher, M. Armand, J. M. Tarascon, Chem. Mater. 2009, 21, 1096-1107.

[23] D. R. MacFarlane, M. Forsyth, P. C. Howlett, M. Kar, S. Passerini, J. M. Pringle, H. Ohno, M. Watanabe, F. Yan, W. Zheng, et al., Nat. Rev. Mater. 2016, 1, 15005.

[24] S. Tyrrell, G. Behrendt, P. Nockemann, Inorg. Chem. 2015, 54, 4495-4503.

[25] S. Tyrrell, M. Swadźba-Kwaśny, P. Nockemann, J. Mater. Chem. A 2014, 2, 2616.

[26] G. Nagaraju, X. Udayabhanu, J. P. Shubha, K. Manjunath, J. Dupont, Int. J. Hydrogen Energy 2017, 43, 4028-4035.

[27] H. Terraschke, J. Olchowka, E. Geringer, A. V. Rodrigues, C. Wickleder, Small 2018, $14,1703707$.

[28] N. O. Nuñez, M. Ocaña, Nanotechnology 2007, 18, 455606.

[29] Z. He, P. Alexandridis, Phys. Chem. Chem. Phys. 2015, 17, 18238-18261.

[30] B. Xin, J. Hao, Chem. Soc. Rev. 2014, 43, 7171-7187.

[31] P. S. Campbell, M. Yang, D. Pitz, J. Cybinska, A. V. Mudring, Chem. - A Eur. J. 2014, $20,4704-4712$.

[32] G. Fiorani, M. Selva, A. Perosa, A. Benedetti, F. Enrichi, P. Licence, T. L. Easun, Green Chem. 2015, 17, 538-550.

[33] A. Samanta, J. Phys. Chem. B 2006, 110, 13704-13716.

[34] J. Y. Kim, O. Voznyy, D. Zhitomirsky, E. H. Sargent, Adv. Mater. 2013, 25, 49865010. 
[35] J. Selling, G. Corradi, Japanese J. Appl. Phys. Yasuo Iwabuchi al Jpn. J. Appl. Phys 1994, 33, 178.

[36] X. Wang, H. Riesen, RSC Adv. 2015, 5, 85506-85510.

[37] S. Hesse, J. Zimmermann, H. Von Seggern, X. Meng, C. Fasel, R. Riedel, J. Appl. Phys. 2009, 105, 63505-83506.

[38] X. G. Meng, Y. S. Wang, D. W. He, J. Nanosci. Nanotechnol. 2010, 10, 2190-2192.

[39] P. Leblans, D. Vandenbroucke, P. Willems, Materials (Basel). 2011, 4, 1034-1086.

[40] H. Riesen, W. A. Kaczmarek, Inorg. Chem. 2007, 46, 7235-7237.

[41] A. Yokozeki, D. J. Kasprzak, M. B. Shiflett, Phys. Chem. Chem. Phys. 2007, 9, 5018.

[42] Q. Liang, Y. Shi, W. Ma, Z. Li, X. Yang, RSC Adv. 2012, 2, 5403.

[43] D. Nicollin, H. Bill, J. Phys. C Solid State Phys. 1978, 11, 4803-4814.

[44] R. S. Eachus, R. H. D. Nuttall, M. T. Olm, W. G. McDugle, F. K. Koschnick, T. Hangleiter, J. M. Spaeth, Phys. Rev. B 1995, 52, 3941-3950.

[45] A. R. Lakshmanan, N. Murase, T. Yazawa, J. Qiu, T. Mitsuyu, K. Hirao, A. Tomita, W. Hoffmann, Radiat. Meas. 2001, 33, 119-127.

[46] H. Riesen, K. Badek, T. Monro, N. Riesen, Opt. Mater. Express 2016, 6, 323-329.

[47] W. Chen, S. Wang, S. L. Westcott, J. Zhang, K. Dou, A. G. Joly, D. E. McCready, J. Appl. Phys. 2005, 97, 1-8.

[48] H. Von Seggern, T. Voigt, W. Knüpfer, G. Lange, J. Appl. Phys. 1988, 64, 1405-1412. 


\section{Figures:}

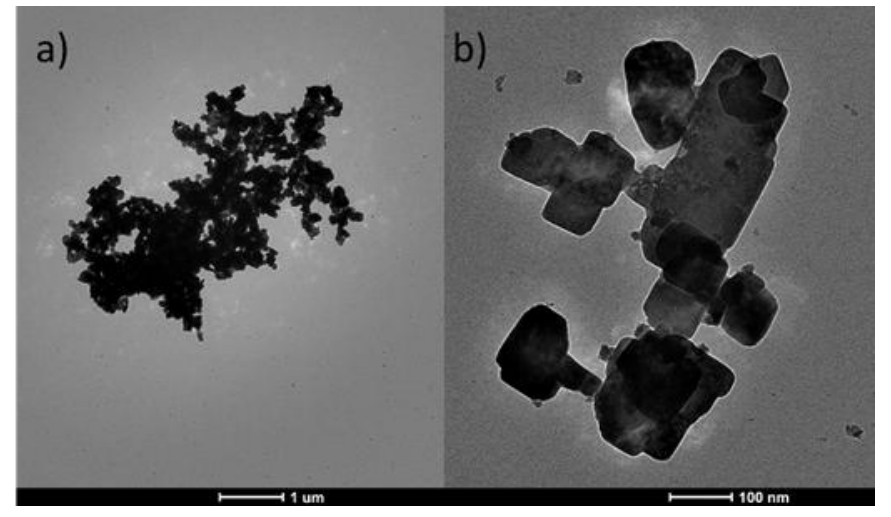

Figure 1a) and b). TEM images of $\mathrm{BaFBr} \mathrm{Eu}^{2+}$ synthesised by ionothermal approach assisted by ultrasound in $\mathrm{BmimBF}_{4}$ ionic liquid media.

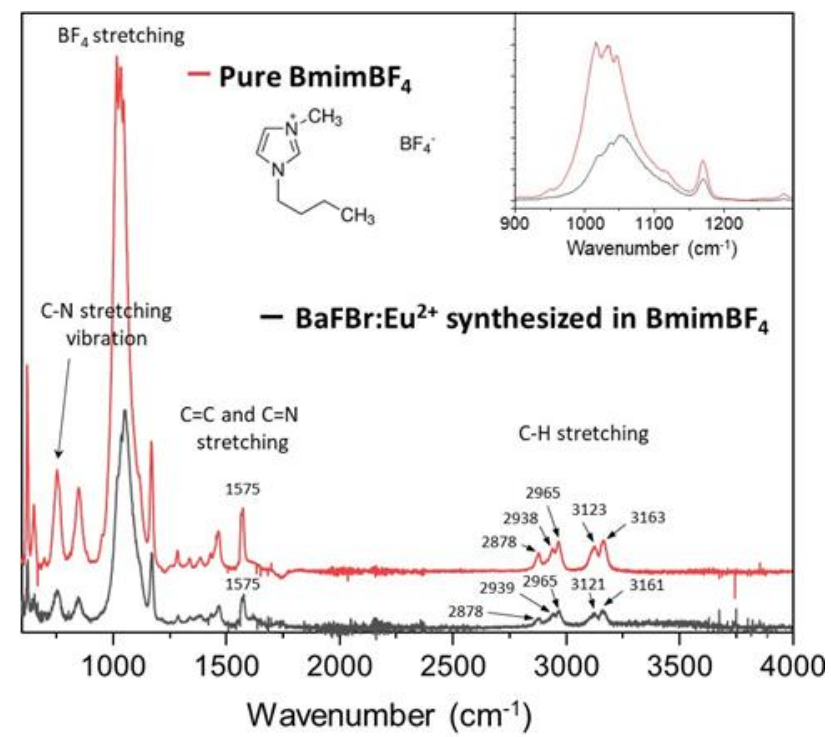

Figure 2. Comparison between FTIR spectra of $\mathrm{BaFBr}: \mathrm{Eu}^{2+}$ synthetized by ionothermal method and pure $\mathrm{BmimBF}_{4}$ ionic liquid. 


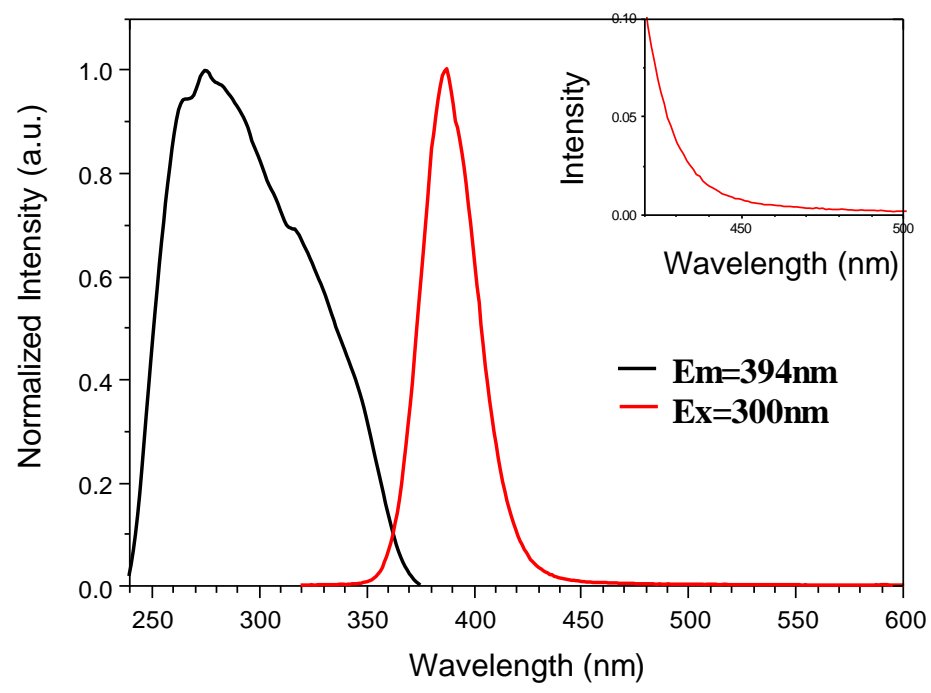

Figure 3. Room temperature excitation (black) and emission (red) spectra of $\mathrm{BaFBr}: \mathrm{Eu}^{2+}$ (doping concentration $2 \mathrm{~mol} \%$ )

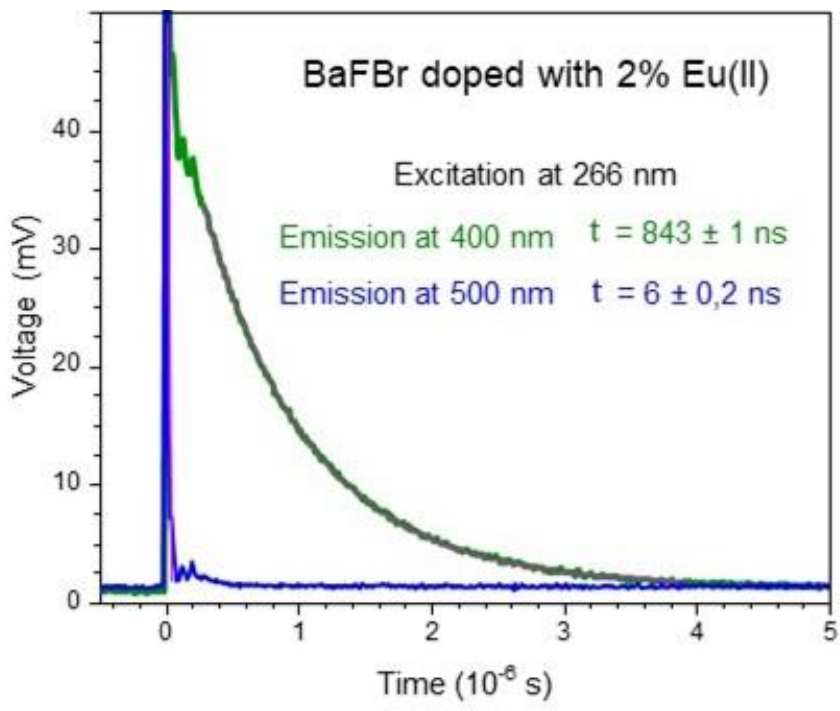

Figure 4. Decay time measurements of $\mathrm{BaFBr}: \mathrm{Eu}^{2+}$ with excitation at $266 \mathrm{~nm}$. A monoexponential lifetime of $843 \mathrm{~ns}$ is found when the detection is fixed at $400 \mathrm{~nm}$ whereas a monoexponential lifetime of $\sim 6 \mathrm{~ns}$ is detected for a detection at $500 \mathrm{~nm}$. Fitting were performed using a monoexponential function and exhibit correlation factor of $\mathrm{R}^{2}=0.99$. 


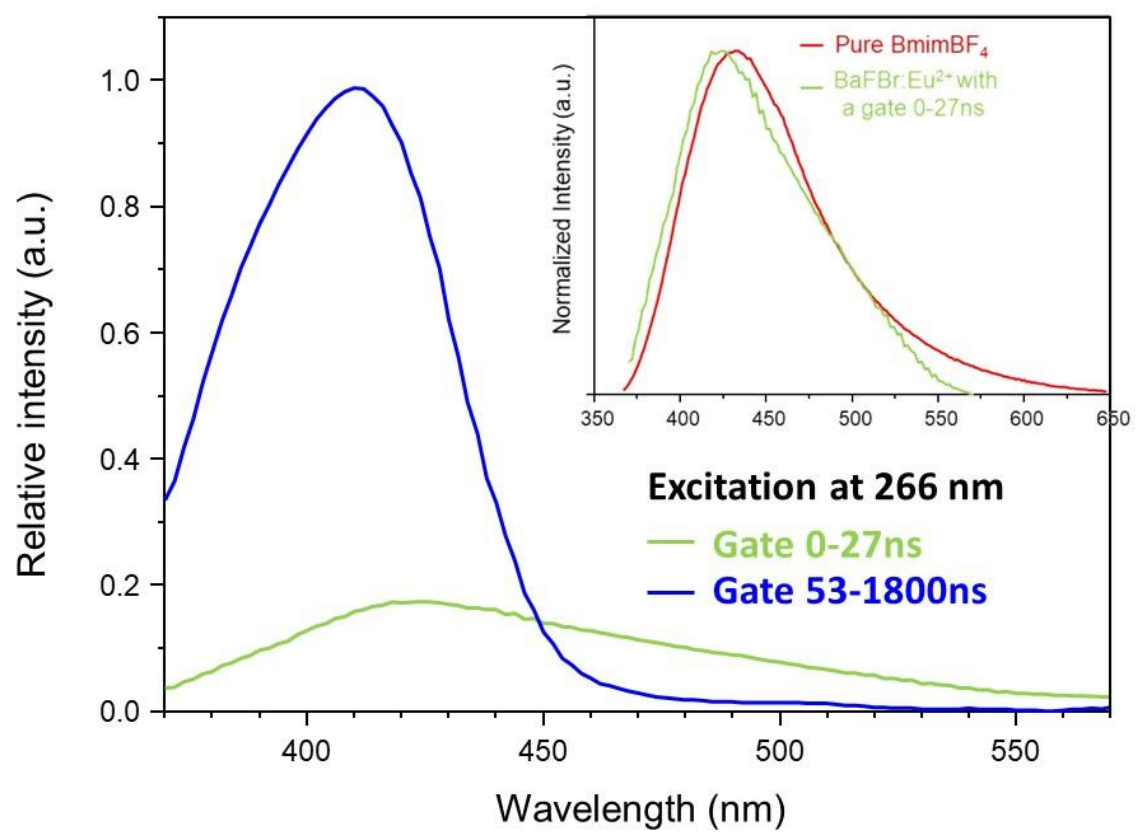

Figure 5. Time resolved luminescence measurements for $\mathrm{BaFBr}: \mathrm{Eu}^{2+}$. Red curve represents the emission with a detection gate 0-27 ns and green curve with a gate 53-1800 ns. The inset shows the comparison of PL between emission measured with the gate 0-27 ns and emission of solely $\mathrm{BmimBF}_{4}$. 
ToC: In this work, an effort is made to understand the improved effect of ionothermal synthesis on the photoluminescence properties of nanophosphors.

Keywords: Ionothermal synthesis, nano-phosphors, time resolved spectroscopy, fluorides

Jacob Olchowka* Hans Hagemann, Teresa Delgado, Claudia Wickleder*

Influence of ionothermal synthesis using $\mathrm{BmimBF}_{4}$ as solvent on nanophosphors BaFBr: $\mathrm{Eu}^{2+}$ photoluminescence

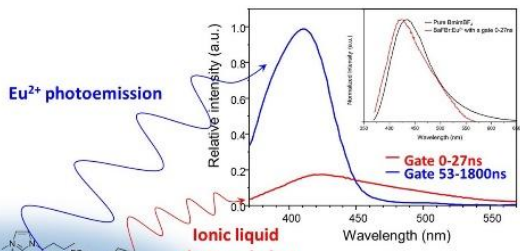


